\title{
Whipple's Disease with Colonic Involvement: A Rare Endoscopic Documentation
}

\author{
Verónica Gamelas ${ }^{a}$ Ines Canha ${ }^{a}$ João Pimentel ${ }^{b}$ Sara Santos $^{a}$ \\ Verónica Borges $^{a} \quad$ Carlos Bernardes $^{a}$ \\ ${ }^{a}$ Gastroenterology Department, Centro Hospitalar Universitário de Lisboa Central, Lisbon, Portugal; b Pathological \\ Anatomy Department, Centro Hospitalar Universitário de Lisboa Central, Lisbon, Portugal
}

\section{Keywords}

Whipple's disease $\cdot$ Endoscopic presentation $\cdot$ Colon inflammation

\section{Doença de Whipple com envolvimento cólico: documentação endoscópica rara}

\section{Palavras Chave}

Doença de Whipple · Apresentação endoscópica . Inflamação cólica

\section{Case Report}

A 78-year-old woman presented with watery diarrhea and weight loss $-20 \mathrm{~kg}, 33 \%$ of body weight - in the previous 5 months. She denied fever or relevant epidemiological context. Her previous history was unremarkable.

Blood analysis showed anemia (hemoglobin $8.4 \mathrm{~g} / \mathrm{dL}$ ), leukocytosis with neutrophilia and high C-reactive protein $(73.8 \mathrm{mg} / \mathrm{L})$.
Fecal analysis was negative for microbiological, parasitological and Giardia presence; fecal calprotectin was unchanged. Magnetic resonance enterography described normal small bowel and colon appearance, mesenteric fat densification and prominent mesenteric ganglia.

Upper endoscopy revealed enlarged duodenal folds, lymphangiectasias, focal hyperemia and friability of the duodenal mucosa (Fig. 1a, b). Ileocolonoscopy revealed continuous edema, hyperemia and friability of the distal ascending colon, associated with erosions and superficial ulcers, as well as a reduced distensibility (Fig. 2b, c). There were no endoscopic alterations in the remaining segments, including the terminal ileum (Fig. 2a). Histological examination of duodenal (Fig. 1c-e), ileal and ascending colonic samples (Fig. $2 \mathrm{~d}-\mathrm{f}$ ) identified the presence of foamy macrophages, with periodic acid-Schiff (PAS)positive intracytoplasmic granules, which were Ziehl-Neelsennegative. Despite having no clinical neurological involvement, Tropheryma whipplei DNA was detected in the cerebrospinal fluid (CSF).

The patient completed a 14-day course of once daily $2 \mathrm{~g}$ intravenous ceftriaxone, followed by a 12 -month course of twice daily $800+160 \mathrm{mg}$ oral trimethoprim-sulfamethoxazole, which is currently under way. Diarrhea resolved in the first weeks of antibiotic therapy, and full weight recovery occurred after 4 months.

\section{(c) 2021 Sociedade Portuguesa de Gastrenterologia} Published by S. Karger AG, Basel

This is an Open Access article licensed under the Creative Common Attribution-NonCommercial-4.0 International License (CC BY-NC) (http://www.karger.com/Services/OpenAccessLicense), applicable to the online version of the article only. Usage and distribution for commercial purposes requires written permission.
Correspondence to:

Verónica Gamelas, veronicagamelas@gmail.com 


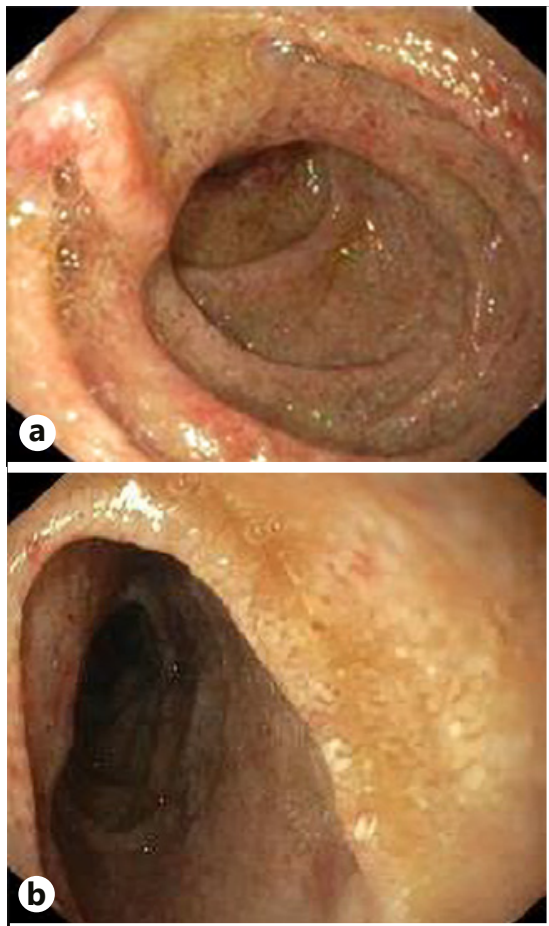

Fig. 1. Upper endoscopy findings and histological examination. a, b Enlarged duodenal folds, lymphangiectasias and focal hyperemia and friability of the duodenal mucosa (c-e) fragment of duodenal mucosa, showing villous thickening due to macrophage cell infiltrate with clear and mucinous cytoplasm, with PAS+ intracytoplasmic granules. Hematoxylin and eosin, $\times 100(\mathbf{c})$ and $\times 400(\mathbf{d})$, and PAS stain, $\times 400(\mathbf{e})$.
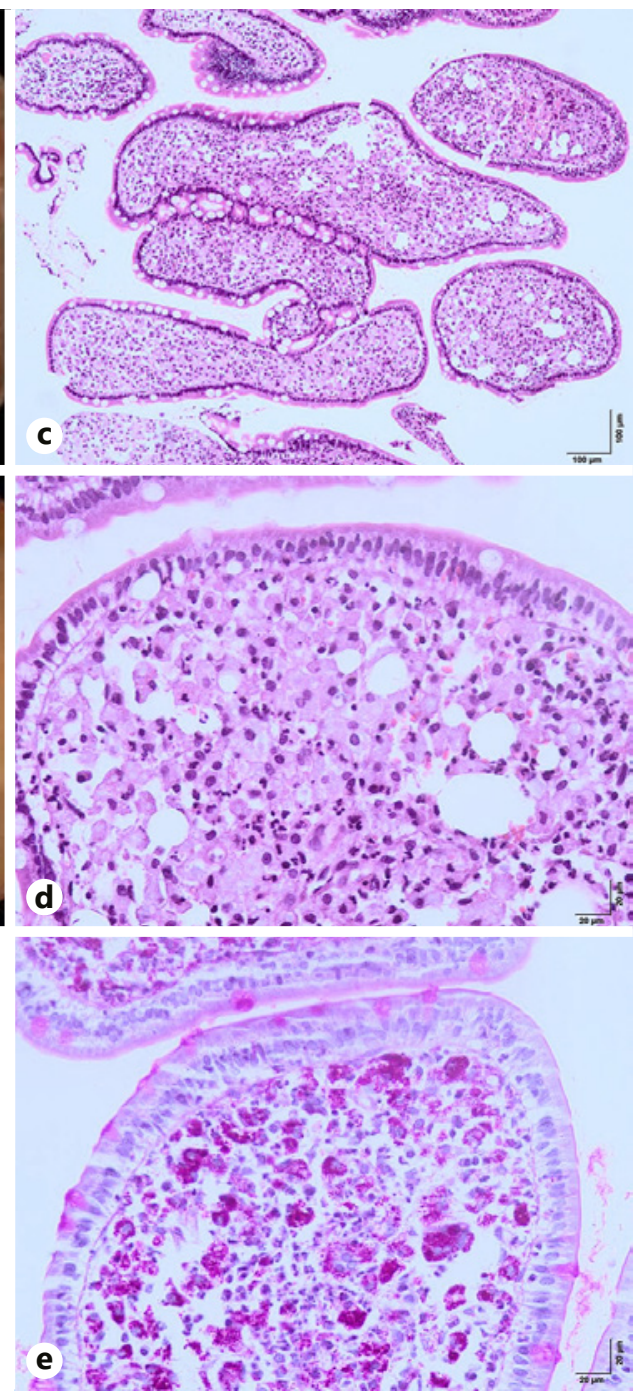

Whipple's disease is a very rare and potentially fatal systemic disease. It usually develops over the course of many years in genetically predisposed patients. The classic presentation is characterized by diarrhea and weight loss, often preceded by joint complaints. Other symptoms include abdominal pain, low-grade fever and adenopathy. The diagnosis is based on characteristic findings in duodenal or jejunal biopsies. Although typical, the presence of foamy PAS-positive macrophages remains nonspecific and may be seen in other infections, particularly in immunocompromised patients, such as Mycobacterium avium, Rhodococcus equi, extrapulmonary pneumocystosis, leishmaniasis and histoplasmosis [1]. Ziehl staining is helpful to exclude Mycobacterium but a definite diagnosis implies T. whipplei identification by a second diagnostic test: immunohistochemistry or identification of bacterial DNA with polymerase chain reaction. The search for the bacteria in the CSF was of diagnostic value in our case. Yet, it is recommended in all cases to accurately evaluate central nervous system (CNS) involvement, which occurs in about half of the patients. In those cases, treatment should include an antibiotic with good penetra- tion of the blood-brain barrier such as co-trimoxazole and should aim PCR negativity, since CNS disease may progress or relapse and is one of the major death causes [2].

Few works have addressed the endoscopic findings in Whipple's disease, which are generally limited to the small bowel [3]. Colonic involvement was rarely described in the literature [4]. A very recent work reports the case of a child with chronic bloody diarrhea and an endoscopic appearance resembling ulcerative colitis, whose histological evaluation was diagnostic for Whipple's disease [5]. In our work, we document small bowel mucosal appearance, as well as colonic endoscopic changes.

\section{Statement of Ethics}

The authors declare that all ethical procedures were followed. Written informed consent was obtained from the patient for publication of this case report and any accompanying images. 
Fig. 2. Lower endoscopy findings and histological examination. a Normal mucosa of the terminal ileum. b Hyperemia, edema and erosions of the ascending colon mucosa. c Edema, friability and reduced distensibility of the ascending colon mucosa. d-f Fragment of colon mucosa, showing infiltration of the chorion by foamy macrophages, with PAS+ intracytoplasmic granules. Hematoxylin and eosin, $\times 100(\mathbf{d})$ and $\times 400(\mathbf{e})$, and PAS stain, $\times 400(\mathbf{f})$.

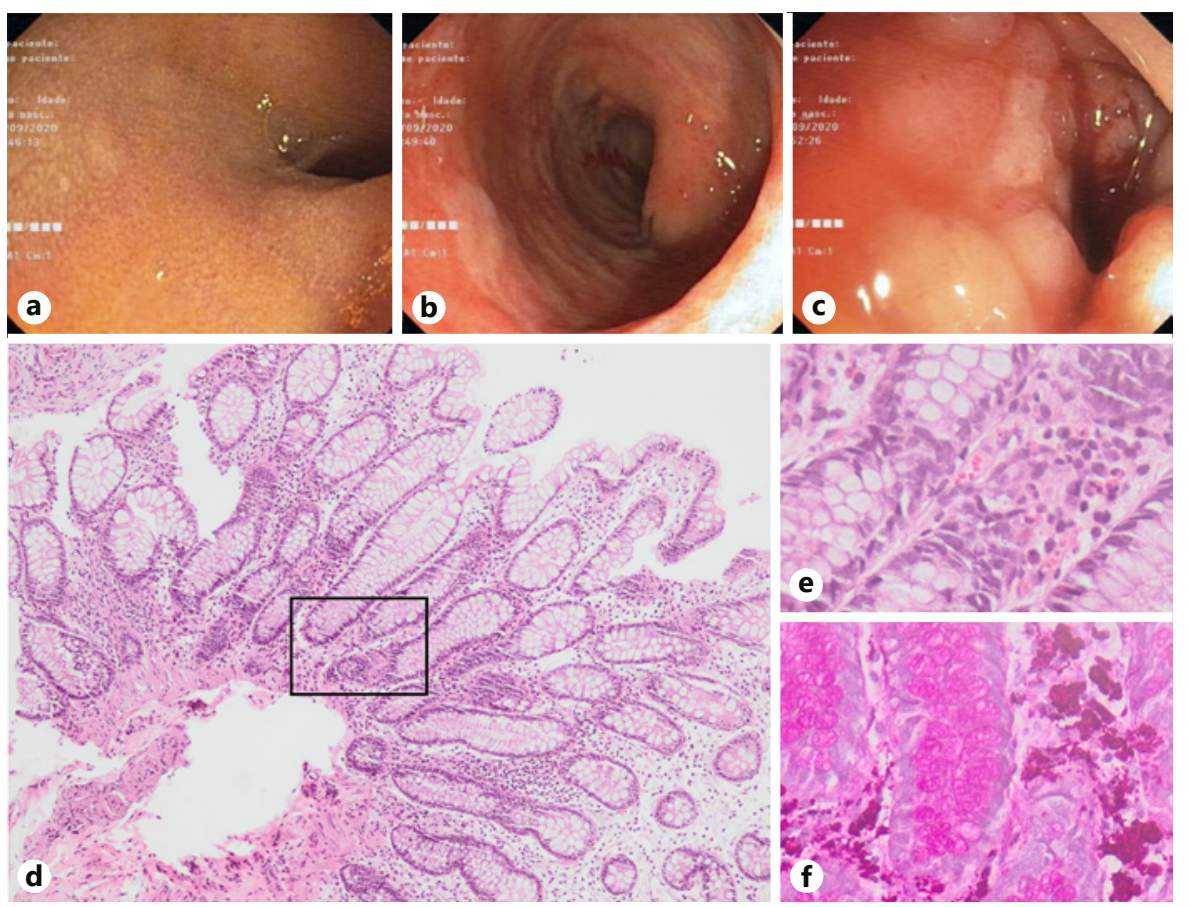

\section{Disclosure Statement}

The authors have no conflicts of interest to declare.

\section{Funding Sources}

There was no grant support for this study.

\section{Author Contributions}

All authors fulfilled all 4 criteria of ICMJE for authorship: acquisition, analysis, or interpretation of data for the work; drafting the work or revising it critically for important intellectual content; final approval of the version to be published; agreement to be accountable for all aspects of the work in ensuring that questions related to the accuracy or integrity of any part of the work are appropriately investigated and resolved.

\section{References}

1 Sagaert X, Tousseyn T, De Hertogh G, Geboes K. Macrophage-related diseases of the gut: a pathologist's perspective. Virchows Arch. 2012 Jun;460(6):555-67.

2 Marth T, Moos V, Müller C, Biagi F, Schneider T. Tropheryma whipplei infection and Whipple's disease. Lancet Infect Dis. 2016 Mar;16(3):e13-22.
3 Mönkemüller K, Fry LC, von Arnim U, Neumann H, Evert M, Malfertheiner P. Whipple's disease: an endoscopic and histologic study. Digestion. 2008;77(3-4):161-5.

4 Marcial MA, Villafaña M. Whipple's disease with esophageal and colonic involvement: endoscopic and histopathologic findings. Gastrointest Endosc. 1997 Sep;46(3):263-6.
5 Tatsuki M, Ishige T, Igarashi $\mathrm{Y}$, Hatori R, Hokama A, Hirato J, et al. Whipple disease mimicking inflammatory bowel disease. Intest Res. 2021 Jan;19(1):119-25. 